\title{
THE DEVELOPMENT OF LANGUAGE AND ITS INTERACTION WITH OTHER ASPECTS OF COGNITION: THE CASE OF MEDIAL WH-QUESTIONS IN ENGLISH AND IN BRAZILIAN PORTUGUESE
}

\author{
Elaine Grolla ${ }^{1^{*}}$ \\ ${ }^{1}$ Universidade de São Paulo, São Paulo, SP, Brasil \\ Adam Liter ${ }^{2 *}$ \\ Jeffrey Lidz ${ }^{2 * * x}$ \\ ${ }^{2}$ University of Maryland, College Park, MD, USA
}

\begin{abstract}
Preschool children acquiring English and Brazilian Portuguese display a peculiar behavior when prompted to produce multi-clause wh-questions. In elicited production tasks, structures with an extra wh-element in medial position are sometimes produced. Such medial questions are impossible in the adult languages being acquired. Following a hypothesis put forth by Grolla \& Lidz (2018), we propose that children's productions are not generated by children's grammar, but reflect difficulties of their developing cognitive system. More specifically, we propose that children's more limited inhibition control capacity leads them to pronounce elements with high activation levels in wrong places of the structure. Experimental data on both languages are provided which corroborate this claim. These data show that children with more limited inhibition control capacity are more likely to produce medial wh-questions.

Keywords: Language Acquisition; Experimental Study; Multi-clause Questions; Inhibition Control Capacity; Speech Production
\end{abstract}

\footnotetext{
"Associate professor of Linguistics at Universidade de São Paulo. Email: egrolla@usp.br. ORCID: 0000-00018126-0493.

${ }^{*}$ PhD student in the Department of Linguistics at the University of Maryland, College Park, MD, USA. Email: io@adamliter.org. ORCID: 0000-0002-1517-2900.

${ }^{* * *}$ Professor of Linguistics at the University of Maryland. Email: jlidz@umd.edu. ORCID: 0000-0001-8829-1495.
} 


\section{Introduction}

Studying the development of language in young children is a daunting task. Young children are not capable of providing judgments on the grammaticality of sentences or discussing the possible meanings a sentence might have. In addition to this lack of meta-linguistic capacity, children are also developing other aspects of cognition, besides language. Thus, when a child produces a non-adult sentence, this might be due to her incomplete knowledge of the language, but it might also be due to her immature extralinguistic cognitive system, such as memory, attention control, inhibition capacity, among others. Therefore, researchers working on language development must bear this in mind when they encounter non-adult linguistic behavior in children.

In this paper, we discuss a case where children acquiring two typologically different languages (English and Brazilian Portuguese (henceforth BrP)) exhibit similar non-adult linguistic behavior. Previous studies on several languages led researchers to posit linguistic explanations for children's errors (see van Kampen, 1997; Jakubowicz \& Strik, 2008 for Dutch; Gutiérrez Mangado, 2006 for Spanish; Oiry, 2006; Demirdache \& Oiry, 2008; Strik, 2003, 2009 inter alia for French, and de Villiers, Roeper \& Vainikka 1990; de Villiers, de Villiers \& Roeper 2011; McDaniel 1989; McDaniel, Chiu \& Maxfield, 1995; Thornton, 1990, 1995 for English). The discussion of the BrP data will shed light on the issue, showing that a non-linguistic explanation, taking into account children's development of other aspects of cognition, is more suited to account for the data.

The linguistic phenomenon under investigation is multi-clause questions, such as the ones below:

(1) a. What do you think that Mary bought?

b. O que você acha que Maria comprou? what you think that Maria bought

'What do you think that Maria bought?'

As we will see in section 2 below, children acquiring English face more challenges than children acquiring $\mathrm{BrP}$, as adult English displays some restrictions on embedded environments that $\mathrm{BrP}$ does not. While at first glance it might be reasonable to assume that an English-acquiring child might be delayed until a late age in learning this part of the target grammar because of its complications, this is not the case for $\mathrm{BrP}$, which has a comparatively simpler grammar. Nonetheless, $\mathrm{BrP}$-acquiring children produce the same sort of non-adult-like sentences.

We will argue that children acquiring English (and $\mathrm{BrP}$ ) are on target with respect to multi-clause wh-questions and that the errors they produce are due to their limited inhibition control capacities. The paper is organized as follows. Section 2 discusses multi-clause questions in both adult languages. Section 3 presents the experiments carried out in English and in BrP. Section 4 discusses these results. Section 5 presents new data on inhibition control. Finally, section 6 concludes the paper. 


\section{Multi-clause questions in adult English and Brazilian Portuguese}

Comparing ((1)a) and ((1)b) above, we might erroneously conclude that English and $\mathrm{BrP}$ have the same restrictions on multi-clause questions. However, when we observe a larger set of data, differences between the two languages become clear. In English, the complementizer 'that' is optional in questions targeting the direct object position, the indirect object position, and adjunct positions, as shown below: ${ }^{1}$

(2) a. Who do you think (that) Mary saw at the party?

b. To whom do you think (that) Mary gave the gift?

c. When do you think (that) Mary will arrive?

For the subject position, however, 'that' is forbidden, a phenomenon called the 'that-trace' effect in the generative literature:'

(3) ${ }^{\star}$ Who do you think that saw the movie?

The sentence above becomes grammatical without 'that':

(4) Who do you think saw the movie?

The 'that-trace' effect is a phenomenon related to the subject position of multi-clause questions. Its name relates to the notion of 'traces', which are theoretical posits in older versions of the generative framework. It was assumed that, when a word moved from its original position to another position in the structure, it left behind a trace, a type of silent element that signals where each word has already been in the structure. ${ }^{3}$ In this framework, when the subject of the subordinate clause moves from its original position to the left periphery of the sentence, it leaves behind a trace (marked as ' $\mathrm{t}$ ' below), which bears the same index as the moved element:

(5) Who do you think that $\mathrm{t}_{1}$ saw the movie?

This configuration characterizes the 'that-trace' filter, which prohibits the complementizer (that) from being followed by a trace. So, the sequence 'that $t^{\prime}$ is not allowed. This filter is operative in some languages, such as English and German, but it is not a universal phenomenon, being absent in Romance languages like BrP, Spanish, Italian, and also in Germanic languages like Dutch (see Chomsky, 1981; Chomsky, 1986; Chomsky \& Lasnik, 1977; Kayne, 1984; among others).

In BrP, no such restriction occurs, and the complementizer 'que' (that) is required in all types of multiclausal questions, including subject questions: 
(6) a. Quem você acha que Maria viu na festa? Who you think that Maria saw at-the party 'Who do you think that Maria saw at the party?'

b. Para quem você acha que Maria deu o presente? To whom you think that Maria gave the gift 'To whom do you think that Maria gave the gift?'

c. Quando você acha que Maria vai chegar? When you think that Maria will arrive? 'When do you think that Maria will arrive?'

d. Quem você acha que viu o filme? Who you think that saw the movie? 'Who do you think that saw the movie?'

So, $\mathrm{BrP}$ is a more uniform language, requiring the complementizer to appear in medial position in all multi-clause questions. In English, there are different requirements, depending on the syntactic position being questioned. The picture in English is even more complex than that, however. If we consider the possibilities for relative clauses (a structure where the complementizer 'that' also appears), more complications emerge.

In relative clauses, we can have either wh-operators (like who, whom, where, which) filling the beginning of the relative clause or we can have the complementizer 'that'. Focusing solely on relatives initiated by 'that', we can see below that the syntactic position being targeted also interferes with how this medial position might be filled:

(7) a. Object: this is the boy (that) Mary saw

b. Adjunct: this is the day (that) Mary will arrive

c. Subject: this is the person that $t$ saw the movie

d. Subject: ${ }^{\star}$ this is the person $t$ saw movie

Relative clauses related to object and adjunct positions have 'that' optionally. For subject position, 'that' is obligatory, as the ungrammaticality of $((7) \mathrm{d})$ shows. So, English has opposing requirements when it comes to the subject position: in multi-clause questions, 'that' is forbidden, but in relative clauses, 'that' is obligatory (something that is called the 'anti that-trace effect').

BrP bears no such complications for relative clauses. We can either have whoperators, like 'quem' (who), 'o que' (which), 'onde' (where), or we can have the complementizer 'que'. In these relatives with 'que', there is no special requirement for the subject position or to any other position. 'Que' is obligatory in all of them, and the sentences become ungrammatical without it: 
(8) a. Object: esse é o menino que Maria viu

this is the boy that Maria saw

'this is the boy that Maria saw'

b. Adjunct: esse é o dia que Maria vai chegar

this is the day that Maria will arrive

'this is the day that Maria will arrive'

c. Subject: esse é o amigo que viu o filme

this is the friend that saw the movie

'this is the friend that saw the movie'

In sum, the complementizer 'que' is always required in multi-clause questions and in relative clauses. The complications discussed for English as opposed to the lack of them in BrP might lead one to predict that children acquiring English will have more difficulty with multi-clause questions than children acquiring BrP. However, this prediction does not take into account other aspects involved in sentence production. We will argue that sentence production, especially the production of multi-clause sentences, imposes demands that are hard for children, no matter the language being acquired. In this sense, both groups are predicted to have difficulties.

In order to investigate this matter, two experimental studies were conducted, one with children acquiring English as their mother tongue and another with children acquiring $\mathrm{BrP}$ as their mother tongue. They are discussed in the next section.

\section{Experiments: children's production of multi-clause questions}

\subsection{English ${ }^{4}$}

In order to investigate children's production of multi-clause questions, we used a protocol that has already been used in several other studies, such as Thornton (1990) and van Kampen (1997). The method was an elicited production task in which children were prompted to ask questions to a puppet (called Snug the Snail). The experimenter showed short videos to the child, but the puppet could not see them. After a video was presented, the experimenter encouraged the child to ask a question to the puppet related to what was in the video, as illustrated below:

(9) Experimenter: we know that it was the girl who was under the top hat,

but Snug the Snail doesn't know that. Ask him who he thinks.

Child (expected): who do you think was under the top hat? 
Puppet: the boy!

Child: Wrong!

There were 18 multi-clause questions to be produced by each child: 6 subject wh-questions, 6 direct object wh-questions, and 6 adverbial wh-questions.

The subjects were 32 children between 3.7 and 6.2 years of age acquiring English as their native language. The study was conducted in Maryland, MD, EUA. Children were recruited from the Center for Young Children (CYC), at the University of Maryland, College Park.

This method was extremely successful in eliciting multi-clause questions from children. All of the children produced adult-like questions, like the ones shown below:

(10) a. What do you think she was eating? (J, 5.2)

b. Who do you think kissed the boy? (C, 4.2)

c. Where do you think the girl was? $(\mathrm{N}, 4.1)$

d. How do you think the boy flew? $(S, 4.6)$

e. Which game do you think they were playing? (W, 4.11)

From the 32 children interviewed, 14 produced non-adult wh-questions, like the ones below:

(11) a. Which kid do you think who got him out of the water? $(A, 6.0)$

b. What do you think what the girl did to the boy? $(\mathrm{S}, 4.7)$

c. What do you think where the girl was walking? $(\mathrm{S}, 4.7)$

d. Who do you think who kissed the boy? $(\mathrm{M}, 4.0)$

e. What girl you think who kicked the ball to the ground? $(\mathrm{L}, 3.11)$

A total of 41 questions like these were produced. These questions are called 'medial' wh-questions in the literature, as they display an extra wh-word in medial position. Besides medial wh-questions, some children produced multiclause questions violating the 'that-trace' filter:

(12) a. Who do you think that was chasing the boys? (J, 5.2)

b. Who do you think that fell from the rope? $(S, 5.9)$

c. Who do you think that kissed the boy? $(\mathrm{A}, 5.4)$

In general, children refrained from filling this medial position. Out of the 571 multi-clause questions produced, only 53 had 'that' in medial position. Of these 53 questions, 30 were licitly filled with 'that' (as illustrated below) and 23 were violations of the that-trace filter.

(13) a. What game do you think that they were playing? (S, 4.8)

b. Where do you think that the girl saw the boy? $(S, 5.9)$ 
Summing up all the non-adult questions produced (medial wh-questions + that-trace filter violations), we have 64 questions, $11 \%$ of the total of multi-clause questions. In the next section, we will discuss the experiment conducted with BrP children.

\section{2. $\mathrm{BrP}$}

The subjects were 72 children between 4.2 to 6.5 years of age acquiring $\mathrm{BrP}$ as their native language. The study was conducted in São Paulo, Brazil. Children were recruited from the Creche e Pré-escola Central, at the University of São Paulo, Butantã campus.

The same videos and the same protocol used in English were used in BrP.

Similar to what happened in English, the method was very successful in BrP and almost all of the children produced multi-clause questions in an adult fashion:

(14) a. Que jogo você acha que eles tavam jogando? (I, 5.2)

What game you think that they were playing

'What game do you think that they were playing?'

b. Quem você acha que voou? (G, 6.2)

Who you think that flew

'Who do you think flew?'

c. Onde você acha que o Cebolinha viu a Mônica? (T, 5.5)

Where you think that the Cebolinha saw the Monica

'Where do you think that Cebolinha saw Monica?'

Out of the 70 participants who produced multi-clause questions, 31 asked at least one medial wh-question. Examples of these questions are provided below:

(15) a. Quem você acha quem tava atrás da cerca? (J, 4.6)

Who you think who was behind of-the fence

'Who do you think was behind the fence?'

b. Como você acha como o Cebolinha cortou a corda? $(G, 4.5)$

How you think how the Cebolinha cut the rope

'How do you think that Cebolinha cut the rope?'

c. Onde você acha onde que o Cascão tava andando? (C, 5.3)

Where you think where that the Cascão was walking

'Where do you think that Cascão was walking?'

Children did not make the mistake of leaving the medial position empty. This position was filled either with 'that' (as in adult language) or with a wh-word 
(non-adult medial wh-questions). A total of 1083 multi-clause questions were produced. 104 of them were medial wh-questions (9.6\%).

\section{Discussion}

As the results show, in both languages children were able to produce a large number of multi-clause questions in an adult-like fashion. By four years of age, all of the children interviewed produced these questions.

However, besides producing grammatical sentences, children also produced some questions that are not possible in the target languages. In $\mathrm{BrP}$, these questions involved pronouncing an extra wh-phrase in the intermediate position of the sentence. In English, children also produced these kinds of questions and questions with violations of the that-trace filter. The difficulties children acquiring English face are not surprising, since the target language displays additional restrictions. However, in $\mathrm{BrP}$, given the uniformity of the language, should we be surprised that children also made mistakes?

There are at least two ways to explain this fact. One is to postulate that the behavior found in English and $\mathrm{BrP}$ are due to completely different reasons. The other is to try to search for one single explanation that accounts for the behavior of both groups of children.

The first strategy is carried out by Thornton (1990), who only studied children acquiring English and was the first study to capture this kind of behavior. Her explanation was that children have knowledge of the that-trace filter, but are still in the process of figuring out which lexical elements are complementizers. That is, children use wh-words in the place of 'that', as part of lexical acquisition. Given the variability found in their input, children's non-adult productions would indicate their attempts to obey the filter.

This proposal has several problems, ${ }^{5}$ but the more obvious one in the context of the experiments discussed above is that it cannot account for the $\mathrm{BrP}$ data. Given that there is no that-trace filter in $\mathrm{BrP}$ and the language is extremely regular with respect to the complementizer position in embedded contexts, the use of wh-words in intermediate position should be related to something else.

In an attempt to account for the facts in both languages in a uniform way, we follow Grolla \& Lidz (2018) who related the medial questions produced by children acquiring English to their immature cognitive system. More specifically, Grolla \& Lidz proposed that children's medial wh-questions are related to their immature inhibition control capacities. In order to entertain their proposal in detail, in what follows, we first discuss the mechanisms involved in sentence production and then discuss aspects of inhibition control.

\subsection{Mechanisms of sentence production}

The processes involved in speech production can be grouped into three main tasks: conceptualizing (planning the conceptual content of the message), 
formulating (translating meaning content into sentence form), and articulating (where syntactic and morphological structures from the formulator system are overtly articulated) (see, for example, Kempen \& Hoenkamp, 1987). Levelt (1989) discusses how, at these processing levels, stored forms (be it words or phonemes) are accessed to make them available to the next level. Dell (1986) proposes that these levels are connected in a network. The nodes within this network vary in their activation (or energy). When a word (or phoneme) is activated, activation spreads to other related nodes. Dell's model is organized into four levels: semantic, syntactic, morphological, and phonological. These levels have nodes that are permanently available in long-term memory. When a node is activated, it can spread its activation to connected nodes at other levels. At the syntactic level, nodes correspond to lemmas and their features. At the morphological level, they correspond to roots and affixes. At the phonological level, they correspond to syllabic constituents and phonemes.

The change from one level to another is done by spreading the activation. After a node has been selected and its activation has been increased and spread, the activation returns to zero. But it can be quickly reactivated, as in the case of items that are repeated in a structure.

Dell's theory explains what happens in cases of slips of the tongue, which Grolla \& Lidz propose have a similarity with the phenomenon of children's medial questions. Slips of the tongue, or lapses, are pronunciation errors, like 'beef noodle' pronounced 'beef needle' or 'blue bug' pronounced 'blue blug.'

Dell notes that there is no failure in any of the processes involved in speech production in the case of lapses. They occur when a wrong item is more active than the correct one and is selected. Given that numerous nodes are activated at the same time, this increases the chances of speech errors. For a wrong item to be selected, it must be a member of the same category as the correct item.

In addition to involving different units (words, morphemes, sounds), lapses can have different natures. Some errors, called syntagmatic or contextual errors, involve elements that will be pronounced, but end up being pronounced in places other than the original ones. Speech errors like 'leading list' (for 'reading list') are called anticipations and they occur when an item to come (from the same category as the correct item) has a higher activation level than the correct item. The same happens for perseverations, the difference being that the interference comes from items already coded that remain activated, like in 'beef needle' (for 'beef noodle').

Non-contextual errors involve the pronunciation of items that should not be in the structure, like 'pass the pepper' pronounced as 'pass the salt'. In this case, the activation of 'pepper' spreads the activation to words of the same semantic field and 'salt' ends up being more active than 'pepper.'

Dell's study does not address wh-questions, but Grolla \& Lidz formulated an analysis for these cases based on his theory. In what follows, we first discuss the syntax of multi-clause questions in the generative framework and then present Grolla \& Lidz's proposal. 
Wh-questions are structures displaying a dependency between the position where the wh-word is pronounced and the position where it is interpreted. Consider the simple wh-question below:

\section{What did Mary buy $<$ what $>$ ?}

The word 'what' is the direct object of the verb 'buy'. In languages displaying wh-movement, like English and $\mathrm{BrP}$, the wh-word is generated as the complement of the verb and moves to the left periphery of the sentence. As such, it ends up being pronounced in one place and interpreted in another. Let us now consider the case of multi-clause questions:

(17) What do you think < what $>$ Mary bought $<$ what $>$ ?

In this case, 'what' moves from the position of direct object of the verb 'bought' to the left periphery. In the generative framework, it is assumed that this movement occurs successive-cyclically. This means that the wh-phrase must stop at every intermediate clause boundary before arriving at its final destination. In the example above, 'what' moves from the complement position of the verb 'bought' to the edge of the embedded clause and, from there, to its final position at the left periphery. The two extra <what $>$ are silent copies, that are left in the positions where the wh-word has already stopped.

Let us consider now what happens from the point of view of speech production. In order to be pronounced as the first word in the sentence, the wh-word must have a high level of activation. Grolla \& Lidz conjecture that, after being pronounced in this position, the wh-word cannot have its activation level decreased, as it will still be necessary later to establish a relation with the verb of the embedded clause. If its level of activation remains high, children might end up pronouncing it again, giving rise to a speech error. In this view, then, children's medial wh-questions are analyzed as speech errors, and not as a lack of linguistic knowledge.

In general, errors such as medial wh-questions are not found with adult subjects. Grolla \& Lidz proposed that the difference between adults and children lies in their inhibition control capacities. Given that children do not have a fully developed inhibition control capacity, it is harder for them to inhibit the pronunciation of an item with a high level of activation. In the next section, we discuss inhibition control in more detail.

\subsection{Inhibition control capacity}

Inhibition control is one of the executive functions of the brain. Diamond (2013) notes that it is inhibition control that allows us, for example, to be able to control attention, behavior, thoughts and emotions to ignore an internal predisposition or an external distraction and, instead, do what is most appropriate or necessary. 
Inhibition control is related to various tasks. For example, attention inhibition control is related to paying attention selectively, focusing on what one chooses and ignoring other stimuli. Motor control involves inhibiting predominant motor responses and, instead of them, performing others in place.

Focusing specifically on cognitive inhibition control, Harnishfeger (1995) defines inhibition control as the process of actively suppressing previously activated content or cognitive processes. Items to be inhibited enter the working memory, are assessed as irrelevant to the objectives of the tasks in process, and are marked as irrelevant in the working memory and suppressed from attempts to resume.

The executive functions of children (including inhibition control) are not fully developed until adolescence (Davidson, Amso, Anderson \& Diamond, 2006). In most of the inhibition control tasks reported in the literature, rates of correct responses increase with age, but rates close to $100 \%$ are only reached around 20 years of age.

Grolla \& Lidz's claim is that children's production of wh-words and complementizers in intermediate position is related to their inhibition control capacity. Speakers must inhibit the pronunciation of words that are active in memory, but should not be spoken. Adults are able to do it, as they have fully developed inhibition control capacity, but children are still developing it and might end up producing these words where they should not.

\section{The relation between inhibition control capacity and sentence production-experimental studies}

Grolla \& Lidz's proposal is that children end up pronouncing the copy in the intermediate position because of their limited inhibition control capacity. The idea is that items that are active in memory are pronounced when speakers produce a sentence. However, the production of sentences also involves inhibiting the pronunciation of other words that are active, but should not be pronounced (as the wh-copies in intermediate positions shown above). Adults can handle this task fairly easily, but children have a harder time, due to their limited inhibition control capacity.

If this hypothesis is on the right track, we should be able to find a relation between children's inhibition control capacity and their production of medial whquestions. In order to test this hypothesis, Grolla \& Lidz tested children on an experiment used in the literature to measure children's inhibition control capacity. The goal was to check whether the children who produced medial questions would be the ones with lower scores on the inhibition control capacity test.

The test for measuring inhibition control was an object naming task, applied following the method described in Kipp \& Poppe (1997). In this experiment, children are introduced to a game where they should name objects shown in a book. The book used was the same used by Kipp \& Poppe, Anno's Journey, a book containing complex images of scenes in a city and no text. Before starting the test, 
a training section, of 30 seconds, was applied, to get the child familiarized with the task. Following the familiarization phase, the experiment, which consisted of two parts, started. In the first part, that lasted two minutes, children should not name distracting items (the animals shown in the book). If an animal was pointed out in the book, the child should not name it. She should name all the other things pointed out, such as people, vehicles, plants, objects, toys, etc. In the second part of the test, that also lasted two minutes, the child had to name all the items indicated on the pages of the book, including animals. The measure in this task is whether the child pronounced (or not) distractors in the first part of the test. The second part of the task was a control to ensure that children were not merely biased against naming animals.

In this task, the child must consciously inhibit the tendency to pronounce the names of animals that she sees in the book. Note that words that cannot be named have a high level of activation, as children see their images in the book and probably name them internally. In this task, the kind of inhibition required resembles the inhibition involved in producing multi-clause questions. In the case of wh-questions, the inhibition of words with a high level of activation is not conscious; in the case of naming objects seen in the book, it is conscious, since this is the rule of the game that the child must follow.

If the production of medial wh-questions is related to reduced inhibition control capacity, as Grolla \& Lidz (2018) hypothesized, then there should be an association between the behavior of each child in the linguistic test and on the inhibition control test. That is, children who produce medial wh-questions should be the ones with lower inhibition control capacity.

Grolla \& Lidz separated the children into two groups: the group who produced medial wh-questions and the ones who did not. Then, the authors observed how each child in each group fared with respect to the inhibition control test. We can observe this separation in the contingency table below:

Table 1: Contingency table - Medial wh-questions x Inhibition control (English, $\mathrm{N}=32$ )

\begin{tabular}{|l|l|l|l|l|}
\hline \multirow{2}{*}{ English } & \multicolumn{2}{|l|}{ Production of Medial Wh-Questions } & \\
\cline { 3 - 5 } \multicolumn{2}{|c|}{} & Yes & No & Total \\
\hline Inhibition Task & Yes & $\mathbf{9}$ & 4 & 13 \\
\cline { 2 - 5 } & No & 5 & $\mathbf{1 4}$ & 19 \\
\hline & Total & 14 & 18 & $\mathbf{3 2}$ \\
\hline
\end{tabular}

This table shows that 9 children produced medial wh-questions and also named distractors in the inhibition task. 14 children did not produce medial whquestions and did not name distractors. 4 children did not produce medial whquestions, but named distractors in the inhibition control task and 5 children produced medial questions but did not name distractors. The shaded cells indicate the behaviors that should have the highest number of subjects, if there is a relation between these two tasks. It turns out that, indeed, children who name 
distractors and children who do not are not equally likely to produce medial whquestions (two-tailed Fisher exact test, $\mathrm{p}=0.0293$ ); instead, children who name distractors are more likely to produce medial wh-questions, and children who do not name distractors are less likely to produce medial wh-questions.

Turning now to the study conducted with children acquiring BrP, in the present study we carried out the same inhibition control capacity test and the results are shown in the contingency table below:

Table 2: Contingency table - Medial wh-questions x Inhibition control (BrP, N $=72)$

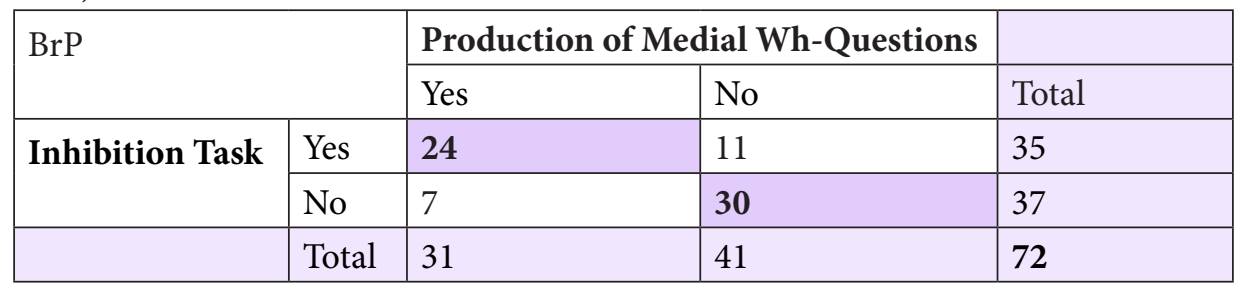

Similar to what Grolla \& Lidz obtained for English, in the present study, we observe that the $\mathrm{BrP}$ children who produced medial wh-questions tend to fare worse on the inhibition control capacity task. 24 children produced medial whquestions and also named distractors in the inhibition task. 30 children did not produce medial wh-questions and did not name distractors. 11 children did not produce medial wh-questions, but named distractors in the inhibition control task and 7 children produced medial questions but did not name distractors. Given the higher number of subjects, the statistical result was even stronger in BrP: two-tailed Fisher exact test, $\mathrm{p}=0.0001$.

These results show a similar behavior of children acquiring two different languages. An explanation for the behavior of children acquiring English based on linguistic knowledge alone would not account for the $\mathrm{BrP}$ and would not account for the relation between the behavior in the linguistic task and in the inhibition control task.

The BrP data corroborates Grolla \& Lidz's claim that children's production of medial wh-questions is not related to the that-trace filter. Children's knowledge is on target with respect to multi-clause questions. Their non-adult behavior is due to extra-linguistic factors that interact with language production.

\section{Concluding remarks}

The results reported in the previous sections are enlightening, as they show that executive function, in particular, inhibition control, plays an important role in children's linguistic behavior. As children grow older, their inhibition control capacity improves and they are able to deal with multi-clause questions without producing medial whquestions. Data from BrP, a language not related to English, indicate that Grolla \& Lidz's analysis for English is on the right track. We are able to account for similar data from two different languages when we look to another aspect of the developing brain 
outside language. We could characterize the data discussed in this paper by saying that we have one developmental explanation for the same phenomenon that occurs in the acquisition process of two typologically different languages.

\section{Acknowledgments}

We would like to thank the anonymous reviewer for his/her suggestions. We also would like to thank the children who participated in the experiments and the schools (Creche e Pré-escola Central, at the University of São Paulo, Butantã campus and the Center for Young Children (CYC), at the University of Maryland, College Park) for their help and support. This research was supported by the National Council for Scientific and Technological Development (CNPq), grant \# 308397/2017-7, to the first author. The second author was also supported by the NSF NRT award DGE-1449815, during the writing and revising of this paper.

\section{Notes}

1. Parentheses indicate that the lexical item is optional.

2. The asterisks indicate that the sentence is not grammatical to native speakers.

3. In more modern versions of the framework, moved elements are said to leave copies behind. So, although traces are not used to describe the structure anymore, the name of the original theoretical notion is still used to name the restriction.

4. The English study presented in this section was first published in Grolla \& Lidz (2018).

5. We refer the reader to Grolla \& Lidz (2018) for further discussion on Thornton's (1990) proposal.

\section{References}

Chomsky, N. (1981). Lectures on government and binding. Foris, Dordrecht.

Chomsky, N. (1986). Barriers. MIT Press.

Chomsky, N., \& Lasnik, H. (1977). Filters and control. Linguistic Inquiry, 8, 425-504.

Davidson, M.C., Amso, D., Anderson, L.C., \& Diamond, A. (2006). Development of cognitive control and executive functions from 4-13 years: Evidence from manipulations of memory, inhibition, and task switching. Neuropsychologia, 44, 2037-2078.

Demirdache, H., \& Oiry, M. (2008). On the syntax and semantics of LD questions in child French. In Anna Gavarró \& Maria João Freitas (Eds.), Language acquisition and development: Proceedings of GALA 2007 (pp. 177-188). Newcastle: Cambridge Scholars Publishing.

De Villiers, J., Roeper, T., \& Vainikka, A. (1990). The acquisition of long-distance rules. In L. Frazier \& J. De Villiers (Eds.), Language processing and language acquisition (pp. 257-297). Dordrecht: Kluwer.

De Villiers, J., de Villiers, P., \& Roeper, T. (2011). Wh-questions: Moving beyond the first phase. Lingua, 121, 352-366.

Dell, G. S. (1986). A spreading-activation theory of retrieval in sentence production. Psychological Review, 93, 283-321. 
Diamond, A. (2013). Executive functions. Annual Review of Psychology, 64, 135-168.

Grolla, E. \& Lidz. J. (2018). A Performance account for medial-wh questions in child English. In Anne B. Betolini \& Maxwell J. Kaplan (Eds.) Proceedings of the 42nd annual Boston University conference on language development (pp. 289-302). ISBN 978-1-57473-086-9.

Gutiérrez Mangado, M. (2006). Acquiring long-distance wh-questions in L1 Spanish: A Longitudinal investigation. In Vincent Torrens \& Linda Escobar (Eds.), The acquisition of syntax in Romance languages (pp. 251-287). Amsterdam: John Benjamins.

Harnishfeger, K. K. (1995). The development of cognitive inhibition: Theories, definitions, and research evidence. In F. N. Dempster \& C. J. Brainerd (Eds.), New perspectives on interference and inhibition in cognition, p. 175-204. San Diego: Academic Press.

Jakubowicz, C., \& Strik, N. (2008). Scope-marking strategies in the acquisition of long distance wh-questions in French and Dutch. Language and Speech, 51, 101133.

Kayne, R. (1984). Connectedness and binary branching. Foris, Dordrecht.

Kempen, G., \& Hoenkamp, E. (1987). An incremental procedural grammar for sentence formulation. Cognitive Science, 11, 201-258.

Kipp, K., \& Poppe, S. (1997). The development of cognitive inhibition in streams-ofconsciousness and directed speech. Cognitive Development, 12, 239-260.

Levelt, W. (1989). Speaking: From intention to articulation. Cambridge, MA: MIT Press.

McDaniel, D. (1989). Partial and multiple wh-movement. Natural Language and Linguistic Theory, 7, 565-604.

McDaniel, D., Chiu, B., \& Maxfield, T. L. (1995). Parameters for wh-movement types: Evidence from child English. Natural Language and Linguistic Theory, 13: 709753.

Oiry, M. (2006). Direct vs. indirect wh-scope marking strategies in French child grammar. In University of Massachusetts Occasional Papers in Linguistics 34, 7796.

Strik, N. (2003). Où tu as caché ton sac? Qu'est-ce que tu penses que je lis? Acquisition des Questions Wh- chez les enfants Francophones de 3 à 6 Ans. [Mémoire de DEA, Université Paris 8 and LPE, Université Paris 5, Boulogne-Billancourt].

Strik, N. (2009). Syntaxe et Acquisition des Phrases Interrogatives en Français et en Néerlandais: une Etude Contrastive. [Doctoral dissertation, Université Paris 8].

Thornton, R. (1990). AdventureS in long-distance moving: The acquisition of complex wh-questions. [Doctoral dissertation, University of Conecticut, Storrs].

Thornton, R. (1995). Referentiality and wh-movement in child English: Juvenile d-linkuency. Language Acquisition, 4, 139-175.

Van Kampen, J. (1997). First steps in wh-movement. [Doctoral dissertation, Wageningen University]. Ponsen and Looijen.

Wright, A., \& Diamond, A. (2014). An effect of inhibitory load in children while keeping working memory load constant. Frontiers in Psychology, 5, 1-9. 
